\title{
Overall Glycemic Index and Glycemic Load of Vegan Diets in Relation to Plasma Lipoproteins and Triacylglycerols
}

\author{
Annika Waldmann ${ }^{\mathrm{a}}$ Alexander Ströhle ${ }^{\mathrm{a}}$ Jochen W. Koschizke ${ }^{\mathrm{a}}$ \\ Claus Leitzmann ${ }^{\text {b }}$ Andreas Hahn ${ }^{a}$ \\ ${ }^{a}$ Nutrition Physiology and Human Nutrition Unit, Institute of Food Science, Centre for Applied Chemistry, \\ University of Hannover, Hannover, and ${ }^{\mathrm{b}}$ Institute of Nutrition Science, Justus Liebig University Giessen, Germany
}

\section{Key Words}

Vegan · Glycemic index · Glycemic load $\cdot$ Lipoproteins •

Triacylglycerol $\cdot$ Dietary fiber

\begin{abstract}
Background: To investigate the overall glycemic index (Gl), glycemic load (GL), and intake of dietary fiber, and to examine the associations between these factors and plasma lipoproteins and triacylglycerols in adult vegans in the German Vegan Study (GVS). Methods: Cross-sectional study, Germany. Healthy men $(n=67)$ and women $(n=87)$, who fulfilled the study criteria (vegan diet for $\geq 1$ year prior to study start; minimum age of 18 years; no pregnancy/childbirth during the last 12 months) and who participated in all study segments. Results: The average dietary GL of the GVS population was 144 , and the average GI was 51.4. The adjusted geometric mean total, $\mathrm{HDL}$, and LDL cholesterol concentrations decreased across the increasing quartiles of GL, carbohydrate and dietary fiber intake. The associations between total cholesterol, HDL cholesterol, LDL cholesterol and GL density and $\mathrm{Gl}$ were inconsistent. Also, associations between $\mathrm{Gl}$, $\mathrm{GL}$, the intake of carbohydrates, and triacylglycerol concentration were not observed. Conclusions: Fiber-rich vegan diets are characterized by a low GI and a low to moderate GL.
\end{abstract}

The data do not support the hypothesis that a carbohydraterich diet per se is associated with unfavorable effects on triaclyglycerols that would be predicted to increase the risk of coronary heart disease.

Copyright $\odot 2007$ S. Karger AG, Basel

\section{Introduction}

To date, coronary heart disease (CHD) remains the leading cause of mortality in high-income countries $[1,2]$ and the prevalence of type 2 diabetes continues to rise by epidemic proportions [3]. There is considerable epidemiological evidence that these diseases are influenced by the life course, and especially by dietary factors $[2,4,5]$. Recently, dietary carbohydrates have received particular attention. Depending on their chemical composition and physical structure, carbohydrates are digested and absorbed at different rates and, therefore, have different physiological effects, especially on blood glucose and insulin concentrations [6].

In order to characterize the rate of carbohydrate absorption after a meal, Jenkins et al. [7] proposed the concept of the glycemic index (GI) as a physiological basis for qualitative classification of carbohydrate-containing

\section{KARGER}

Fax +4161306 1234 E-Mail karger@karger.ch www.karger.com
(C) 2007 S. Karger AG, Basel

0250-6807/07/0514-0335\$23.50/0

Accessible online at:

www.karger.com/anm
Prof. Dr. Andreas Hahn, Nutrition Physiology and Human Nutrition Unit Institute of Food Science, Centre for Applied Chemistry, University of Hannover Wunstorfer Strasse, 14, DE-30453 Hannover (Germany)

Tel. +49511 762 5093, Fax +495117625729

E-Mail andreas.hahn@lw.uni-hannover.de 
foods. The GI is defined as the area under the glucose response curve (AUC) after consumption of a standard amount (50 g) of carbohydrate from a test food, and values are expressed relative to that of a control food (white bread or glucose) $[8,9]$. However, the postprandial blood glucose and insulin response depends both on the quantity and quality of carbohydrates, so there is a rationale to consider them together. Therefore, the concept of the glycemic load (GL) was established by Salmeron et al. [10]. The GL of a selected food is the arithmetic product of its GI and its carbohydrate amount [10]. Several observational studies have shown that the overall GL and/or GI of the diet is/are positively associated with the risk for $\mathrm{CHD}$, unfavorable effects on plasma lipoproteins and triacylglycerols [11-15] and type 2 diabetes [16-18]. In the past, metabolic studies in humans have shown that lowGI diets improve blood glucose levels, urinary C-peptide output [19] and lipid profiles [20-23]. These findings suggest health benefits of plant-based, high-fiber diets with a low GI in the prevention of degenerative diseases like CHD and type 2 diabetes mellitus [4, 6, 24]. There is epidemiological evidence that vegetarians are at low risk for these life course-related diseases and it is believed that this fact is due to the composition of their diet [25-28].

In general, lacto-(ovo-)vegetarians and vegans consume more minimally processed plant foods like fresh fruits, vegetables, whole grain products, legumes and nuts $[29,30]$. Therefore it can be hypothesized that such diets are characterized by a low GI and thus a low GL. Although a large number of studies on vegetarian $[31,32]$ and vegan nutrition $[30,33,34]$ have been published during the last years, only one small study has examined the GI of vegan diets [35]. We therefore investigated the overall GI and GL of such diets assessed by a food-frequency questionnaire (FFQ). Furthermore, this cross-sectional study evaluated the relations of dietary GI and GL as well as total fat, carbohydrate and fiber intakes to plasma concentrations of lipoproteins and triacylglycerols (TG) in 154 apparently healthy adult vegans.

\section{Methods}

\section{Ethical Considerations}

This study was conducted in accordance with the Helsinki Declaration of 1964 as amended in 1996. Since there was no intervention, the Ethic Commission of the State of Lower Saxony decided that an ethical approval was not required. All subjects were volunteers who gave written consent prior to participation and who were free to withdraw from the study at any time.
Subjects: Recruitment and Screening

Participants were recruited by advertisements in eight German magazines. In total, 154 persons took part in all study segments (pre and main questionnaire, FFQ and blood sampling) and fulfilled the following study criteria: vegan diet for at least 1 year prior to the start of the study; a minimum age of 18 years; resident in Germany; no pregnancy or childbirth during the last 12 months. Exclusion criteria were defined as: severe illness during the last 12 months (such as malignant or cardiovascular diseases, renal failure, severe diseases of the gastrointestinal tract), diagnosed blood coagulation disorder, intake of inhibitors of blood coagulation, misuse of alcohol and/or drugs, participation in another study during the last month.

Life course factors (except alcohol consumption; FFQ) were evaluated by means of the study's main questionnaire, in which frequency, duration and kind of physical activity as well as amount of smoking (number of cigarettes per day) were assessed. During the (physical) examinations the participants were screened for health status by a general practitioner (standardized questionnaire with questions regarding (severe) diseases and (minor) complications) in order to screen out the existence of any of the exclusion criteria. Body height and weight were determined by trained personnel. The body weight of participants was measured without shoes and with light clothes using a calibrated SECA scale and recorded to the nearest $0.1 \mathrm{~kg}$; their body height without shoes was determined with a tape measure and recorded to the nearest centimeter. BMI was calculated from weight $(\mathrm{kg})$ divided by height squared $\left(\mathrm{m}^{2}\right)$ of each subject.

\section{Definition of 'Vegan'}

As previously described, participants were classified as vegan when adhering to either a strict vegan $\operatorname{diet}(\mathrm{SV}, \mathrm{n}=98)$ or a moderate vegan diet $(\mathrm{MV}, \mathrm{n}=56)$. The latter was considered a vegan diet when a maximum of 5\% of the ingested energy from eggs, milk and/or dairy products was included [30]. On the one hand, the ingested amounts of eggs $(0.88 \pm 3.31 \mathrm{~g} /$ day $)$, milk and dairy products $(7.95 \pm 10.1 \mathrm{~g} /$ day $)$ in the moderate vegan subgroup was so low that it seemed not to be appropriate to name them restricted lacto-ovo-vegetarians. On the other hand, although all persons reported to be vegans, some persons included food of animal origin in their diet. Moreover, the consumption of eggs, milk and dairy products makes it difficult - if not impossible at all - to name those persons (strict) vegans. Therefore, we decided to name them moderate vegans rather than restricted lacto-ovovegetarians or strict vegans.

\section{Dietary Data Collection}

A slight modification of the validated FFQ used in the Giessen Raw-Food Study [36] was used in the German Vegan Study (GVS) for data collection. The original FFQ was complemented for vegan foods; foods of animal origin - except eggs, butter, milk and dairy products - were excluded. The GVS-FFQ included 199 vegan foods and 7 non-vegan foods such as diary products and eggs. In the GVS-FFQ, common household measures and their equivalents in grams or milliliters were given for each food item. In some cases, portion sizes were made clear with photos or specific comments (i.e. nine strawberries with a size of walnuts weigh $150 \mathrm{~g}$; an orange of the size of a tennis ball equals $250 \mathrm{~g}$ ). In addition, participants were asked for copies of recipes of homemade vegan dishes.
Waldmann/Ströhle/Koschizke/ Leitzmann/Hahn 
Each study participant was asked to complete two estimated 9-day FFQs. In order to minimize seasonal differences, one FFQ was completed in autumn, the other one in spring. As there was no adequate software or database for vegan nutrition to calculate the amounts of ingested nutrients, we developed a piece of software (Paradox database) on the basis of the German nutrient database (BLS II.2). Missing nutritional information of vegan foods and dishes were obtained from the food manufacturers. In the end, 245 foods (incl. 18 beverages) were listed in the database.

\section{Computing the Dietary GI and GL}

For the present analysis, most values of GI (GI $=100$ corresponding to glucose) and GL of the foods were taken from the 'International Table of Glycemic Index and Load' by Foster-Powell et al. [37]. GIs for some foods, for which no published data were available, were estimated using the mean of published indexes from other, similar foods as suggested by Buyken et al. [38]. In these cases, the GL of each food was computed by multiplying the food's GI and the carbohydrate content of one serving. The overall dietary GL for each participant was calculated by multiplying the GL per serving of food by the frequency of consumption and summed these products over all food items to produce the dietary GL. Therefore the formula for the calculation of overall GL is as follows [14]:

$$
\text { Overall dietary } G L=\sum_{I=1}^{n} G I_{i} \times C H O_{i} \times F P D_{i}
$$

where $\mathrm{GI}_{i}$ is the $\mathrm{GI}$ for food $i, \mathrm{CHO}_{i}$ is the carbohydrate content in food; (in grams per serving), and $\mathrm{FDP}_{i}$ is the frequency of servings of food $i$ per day.

The GL density was computed by dividing the dietary GL by energy intake. Additionally, the average GI of the individual's diet, an indicator of the overall quality of carbohydrate intake, was determined. According to Liu et al. [14] the formula for computing the overall dietary GI is the following:

$$
\text { Overall dietary } G I=\frac{\sum_{i=1}^{n} G I_{i} \times \mathrm{CHO}_{i} \times F P D_{i}}{\sum_{i=1}^{n} C H O_{i} \times F P D_{i}}
$$

\section{Evaluation of Lipid Parameters}

Fasting venous blood samples were taken for the measurement of lipid parameters. TG concentrations were measured using an enzymatic colorimetric test (GPO-PAP; Boehringer, Germany). Total cholesterol was assessed also by an enzymatic colorimetric test (CHOD-PAP; Boehringer), while LDL concentrations were measured by precipitation with polyvinylsulfate (Boehringer) and HDL cholesterol by precipitation with phosphotungstic acid (Boehringer).

\section{Statistical Methods}

A statistical analysis program (SPSS 12.0; Chicago, Ill., USA) was used to analyze the data. The results are shown as mean \pm $\mathrm{SD}$ and median plus 5 th/95th percentiles, respectively. The following two-tailed tests at the 5\% level of significance were employed to evaluate the data: in case of skewness the Mann-Whitney $U$ test was used to evaluate differences between the two subgroups (SV and MV). Given normal distribution, the independent sample $t$ test was taken. Normal distribution of data was checked visually and by using the Kolmogorov-Smirnov test. Dealing with nominal data, the $\chi^{2}$ test was employed to evaluate statistically significant differences. For the subgroups characterized by the quartiles of average dietary GL, GL density, average dietary GI as well as intake of carbohydrate and dietary fiber, the Kruskal-Wallis test was carried out to reveal statistically significant differences regarding the demographic, life course, and biochemical factors. Using multiple linear regressions the plasma concentrations of TG, total cholesterol, HDL and LDL cholesterol were adjusted for potential confounding factors including age, BMI, cigarette smoking, alcohol intake, physical activity, intakes of energy, dietary fiber, protein, saturated, monounsaturated, and polyunsaturated fatty acids. The adjusted geometric means were calculated by first regressing the natural logarithm of plasma concentrations on dietary variables and by exponentiation of the resulting mean concentrations.

Because of the low variability in BMI (5th percentile: 17.5 $\mathrm{kg} / \mathrm{m}^{2}$, 95th percentile: $25.4 \mathrm{~kg} / \mathrm{m}^{2}$ ), analyses were not repeated with subjects stratified by BMI classes.

\section{Results}

Of the recruited subjects, $56.5 \%$ were females (SV $\left.51.0 \%, \mathrm{MV} 66.1 \%, \mathrm{p}=0.07, \chi^{2}\right)$. Furthermore, the two subgroups did not differ in their mean BMI and their mean age. Participants reported a total carbohydrate intake of $274 \pm 90.3 \mathrm{~g} /$ day, which contributed $57.1 \pm 7.48 \%$ to dietary energy. Computed dietary fiber intake was 56.7 $\pm 7.74 \mathrm{~g} /$ day. The average dietary GL was $144 \pm 47.3$, the mean GL density was $17.7 \pm 3.06$ and the average dietary GI was $51.4 \pm 4.25$. Table 1 shows the corresponding data for the dietary subgroups SV and MV. Strict vegans had significantly higher dietary intakes of polyunsaturated fatty acids (PUFA) and n-6 fatty acids respectively, whereas the intake of cholesterol was significantly lower.

\section{Dietary GI and GL}

Table 2 shows to which extent different food groups contributed to the overall dietary GL. In the total study population, whole grain products and fruits were the main contributors to the GL with a median contribution of 37.8 and $26.3 \%$, respectively. There were no significant differences in age, exercise time, smoking status, and alcohol among the dietary quartiles of GI (neither when the crude GI was used nor when controlling for energy). But among the dietary GLD quartile groups, age distribution was significantly different. In the lowest GLD quartile, persons were older ( $47.8 \pm 15.1$ years $)$ than in the highest quartile $(40.6 \pm 16.1, \mathrm{p}=0.018)$. 
Table 1. Age, BMI, and dietary intakes (total energy intake, relation of macronutrients, fatty acid, fiber and alcohol intake) and dietary GL, GL density and average glycemic index of strict and moderate vegans within the GVS (mean $\pm \mathrm{SD}$ )
Table 2. Percentage contribution of different food groups to the GL within the GVS (median plus 5th/95th percentiles)

\begin{tabular}{lccc}
\hline & $\begin{array}{l}\text { Strict } \\
\text { vegans, } \mathrm{n}=98\end{array}$ & $\begin{array}{l}\text { Moderate } \\
\text { vegans, } \mathrm{n}=56\end{array}$ & $\mathrm{p}$ \\
\hline Age, years & $43.4 \pm 15.4$ & $45.7 \pm 14.2$ & $0.358^{2}$ \\
BMI, kg/m & $21.3 \pm 2.73$ & $21.3 \pm 2.20$ & $0.861^{2}$ \\
Energy intake, MJ/day & $8.59 \pm 2.97$ & $7.60 \pm 2.28$ & $0.033^{2}$ \\
Carbohydrates, \% of energy & $56.4 \pm 7.74$ & $58.6 \pm 6.94$ & $0.146^{2}$ \\
Protein, \% of energy & $11.9 \pm 2.11$ & $11.0 \pm 1.90$ & $0.013^{2}$ \\
Fat, \% of energy & $30.3 \pm 8.22$ & $28.8 \pm 7.02$ & $0.255^{2}$ \\
Saturated fatty acids, \% of energy & $5.91 \pm 1.66$ & $6.16 \pm 1.84$ & $0.377^{2}$ \\
Monounsaturated fatty acids, \% of energy & $12.5 \pm 5.50$ & $12.3 \pm 4.79$ & $0.817^{1}$ \\
Polyunsaturated fatty acids, \% of energy & $9.06 \pm 3.48$ & $7.84 \pm 2.78$ & $0.026^{2}$ \\
n-6 fatty acids, g/day & $19.2 \pm 10.4$ & $14.4 \pm 7.24$ & $0.003^{1}$ \\
n-3 fatty acids, g/day & $1.98 \pm 1.16$ & $1.94 \pm 1.13$ & $0.791^{1}$ \\
Cholesterol, mg/day & $18.0 \pm 28.2$ & $27.8 \pm 23.7$ & $<0.001^{1}$ \\
Fiber, g/day & $58.6 \pm 22.2$ & $53.5 \pm 14.9$ & $0.125^{2}$ \\
Alcohol consumption, g/day & $0.66 \pm 3.15$ & $0.97 \pm 3.13$ & $0.084^{1}$ \\
Average glycemic index & $51.5 \pm 4.51$ & $51.2 \pm 3.81$ & $0.731^{2}$ \\
Average glycemic load & $148 \pm 50.1$ & $136 \pm 41.4$ & $0.135^{2}$ \\
Glycemic load density/per MJ energy intake & $17.6 \pm 3.27$ & $18.0 \pm 2.66$ & $0.337^{2}$ \\
\hline
\end{tabular}

${ }^{1}$ Mann-Whitney U test.

$2 \mathrm{t}$ test for unpaired samples.

\begin{tabular}{llll}
\hline Food group & $\begin{array}{l}\text { Strict vegans } \\
\mathrm{n}=98\end{array}$ & $\begin{array}{l}\text { Moderate vegans } \\
\mathrm{n}=56\end{array}$ & $\mathrm{p}$ \\
\hline Whole grain products & $43.0(1.12 / 61.5)$ & $33.2(2.32 / 62.2)$ & $0.023^{1}$ \\
Refined carbohydrates & $4.81(0 / 23.8)$ & $7.72(0.06 / 26.6)$ & $0.183^{2}$ \\
Fruits & $23.8(7.56 / 73.7)$ & $33.0(8.29 / 76.2)$ & $0.022^{2}$ \\
Vegetables & $12.5(4.50 / 25.7)$ & $13.6(3.40 / 34.9)$ & $0.324^{1}$ \\
Juices & $1.48(0 / 10.4)$ & $1.30(0 / 16.7)$ & $0.924^{2}$ \\
Legumes, soy & $2.09(0 / 8.48)$ & $0.76(0 / 7.42)$ & $0.001^{2}$ \\
Nuts \& seeds & $0.48(0 / 2.46)$ & $0.38(0.01 / 3.34)$ & $0.471^{2}$ \\
Miscellaneous & $2.09(0 / 16.1)$ & $2.90(0 / 12.8)$ & $0.721^{2}$ \\
\hline \multicolumn{1}{c}{${ }^{2}$ t test for unpaired samples. } & & & \\
${ }^{2}$ Mann-Whitney U test. & & & \\
\hline
\end{tabular}

\section{Lipid Profile}

The unadjusted mean fasting TG concentration of the participants was $0.96 \pm 0.72 \mathrm{mmol} / \mathrm{l}(\mathrm{SV} 0.96 \pm 0.80$ $\mathrm{mmol} / \mathrm{l}, \mathrm{MV} 0.95 \pm 0.55 \mathrm{mmol} / \mathrm{l} ; \mathrm{p}=0.724)$. The unadjusted mean plasma total cholesterol concentration was $4.50 \pm 1.08 \mathrm{mmol} / \mathrm{l}(\mathrm{SV} 4.36 \pm 0.97 \mathrm{mmol} / \mathrm{l}, \mathrm{MV} 4.75$ $\pm 1.22 \mathrm{mmol} / \mathrm{l} ; \mathrm{p}=0.044$ ). The unadjusted mean plasma HDL cholesterol concentration was $1.34 \pm 0.34 \mathrm{mmol} / \mathrm{l}$ $(\mathrm{SV} 1.30 \pm 0.33 \mathrm{mmol} / \mathrm{l}, \mathrm{MV} 1.41 \pm 0.34 \mathrm{mmol} / \mathrm{l} ; \mathrm{p}=$ 0.070). The unadjusted mean plasma LDL cholesterol concentration was $2.63 \pm 0.98 \mathrm{mmol} / \mathrm{l}(\mathrm{SV} 2.53 \pm 0.90$ $\mathrm{mmol} / \mathrm{l}, \mathrm{MV} 2.81 \pm 1.09 \mathrm{mmol} / \mathrm{l} ; \mathrm{p}=0.108)$. The unadjusted ratio of total cholesterol to HDL was $3.49 \pm 0.97$ (SV $3.49 \pm 1.02$, MV $3.48 \pm 0.89 ; \mathrm{p}=0.956)$. An association between the intake of saturated fatty acids and the unadjusted concentrations of total, HDL, and LDL cholesterol was found (Spearman correlation coefficient each $\mathrm{r}<0.3, \mathrm{p}<0.5$ ). Therefore, the multivariate models were - besides other factors - adjusted for the intake of saturated, monounsaturated, and polyunsaturated fatty acid intake. 
Table 3. Geometric mean plasma concentrations of TG, total cholesterol, HDL and LDL cholesterol across the quartiles of dietary GL, GL density and average GI in apparently healthy participants of the GVS ${ }^{1}$

\begin{tabular}{|c|c|c|c|c|c|}
\hline & $\begin{array}{l}\text { Triacylglycerol } \\
\mathrm{mmol} / \mathrm{l}\end{array}$ & $\begin{array}{l}\text { Total cholesterol } \\
\mathrm{mmol} / \mathrm{l}\end{array}$ & $\begin{array}{l}\text { HDL cholesterol } \\
\mathrm{mmol} / \mathrm{l}\end{array}$ & $\begin{array}{l}\text { LDL cholesterol } \\
\mathrm{mmol} / 1\end{array}$ & TC:HDL ratio \\
\hline \multicolumn{6}{|c|}{ Quartile of $\mathrm{GL}^{3}$} \\
\hline $\mathrm{Q}_{1}[87.9]$ & $0.83(-1.19 / 2.85)$ & $4.92(2.92 / 6.92)$ & $1.44(-0.55 / 3.43)$ & $2.87(0.83 / 4.90)$ & $3.42(1.41 / 5.42)$ \\
\hline $\mathrm{Q}_{2}[129]$ & $0.81(-1.21 / 2.82)$ & $4.39(2.39 / 6.40)$ & $1.34(-0.66 / 3.34)$ & $2.45(0.42 / 4.48)$ & $3.17(1.29 / 5.28)$ \\
\hline $\mathrm{Q}_{3}[154]$ & $0.84(-1.18 / 2.85)$ & $4.29(2.29 / 6.30)$ & $1.28(-0.71 / 3.27)$ & $2.39(0.36 / 4.43)$ & $3.35(1.35 / 5.35)$ \\
\hline $\mathrm{Q}_{4}[206]$ & $0.88(-1.13 / 2.89)$ & $3.97(1.96 / 5.97)$ & $1.15(-0.84 / 3.14)$ & $2.18(0.15 / 4.22)$ & $3.43(1.43 / 5.42)$ \\
\hline $\mathrm{p}^{2}$ & 0.199 & $<0.001$ & $<0.001$ & $<0.001$ & 0.363 \\
\hline \multicolumn{6}{|c|}{ Quartile of GL density ${ }^{3,4}$} \\
\hline $\mathrm{Q}_{1}[13.9]$ & $0.79(-1.23 / 2.80)$ & $4.42(2.41 / 6.42)$ & $1.35(-0.65 / 3.36)$ & $2.50(0.47 / 4.53)$ & $3.27(1.27 / 5.27)$ \\
\hline $\mathrm{Q}_{2}[16.8]$ & $0.85(-1.16 / 2.85)$ & $4.39(2.37 / 6.40)$ & $1.29(-0.71 / 3.29)$ & $2.52(0.47 / 4.57)$ & $3.39(1.39 / 5.38)$ \\
\hline $\mathrm{Q}_{3}[18.6]$ & $0.83(-1.19 / 2.86)$ & $4.39(2.38 / 6.40)$ & $1.30(-0.70 / 3.30)$ & $2.47(0.43 / 4.51)$ & $3.38(1.37 / 5.38)$ \\
\hline $\mathrm{Q}_{4}[21.7]$ & $0.88(-1.13 / 2.89)$ & $4.33(2.32 / 6.33)$ & $1.25(-0.75 / 3.26)$ & $2.35(0.31 / 4.39)$ & $3.44(1.45 / 5.43)$ \\
\hline $\mathrm{p}^{2}$ & 0.100 & 0.849 & 0.269 & 0.491 & 0.438 \\
\hline \multicolumn{6}{|c|}{ Quartile of average $\mathrm{GI}^{3}$} \\
\hline $\mathrm{Q}_{1}[46.3]$ & $0.82(-1.20 / 2.83)$ & $4.43(2.42 / 6.45)$ & $1.32(-0.69 / 3.33)$ & 2.46 & $3.36(1.36 / 5.35)$ \\
\hline $\mathrm{Q}_{2}[49.8]$ & $0.81(-1.21 / 2.82)$ & $4.32(2.31 / 6.32)$ & $1.31(-1.11 / 3.73)$ & $2.41(0.37 / 4.44)$ & $3.29(1.29 / 5.29)$ \\
\hline $\mathrm{Q}_{3}[52.5]$ & $0.85(-1.69 / 3.38)$ & $4.34(2.35 / 6.36)$ & $1.29(-0.70 / 3.29)$ & $2.45(0.41 / 4.48)$ & $3.36(1.36 / 5.35)$ \\
\hline $\mathrm{Q}_{4}[56.9]$ & $0.88(-1.14 / 2.90)$ & $4.42(2.41 / 6.44)$ & $1.27(-0.73 / 3.27)$ & $2.52(0.47 / 4.58)$ & $3.48(1.47 / 5.48)$ \\
\hline $\mathrm{p}^{2}$ & 0.132 & 0.793 & 0.738 & 0.904 & 0.227 \\
\hline \multicolumn{6}{|c|}{ Quartile of carbohydrate intake ${ }^{3}$} \\
\hline $\mathrm{Q}_{1}[172]$ & $0.83(-1.19 / 2.85)$ & 6.93) & $1.44(-$ & 2.90 & $3.42(1.42 / 5.42)$ \\
\hline $\mathrm{Q}_{2}[239]$ & $0.80(-1.21 / 2.82)$ & $4.44(2.44 / 6.45)$ & $1.36(-0.64 / 3.35)$ & $2.48(0.45 / 4.51)$ & $3.29(1.29 / 5.28)$ \\
\hline $\mathrm{Q}_{3}[289]$ & $0.84(-1.18 / 2.86)$ & $4.23(2.22 / 6.23)$ & $1.26(-0.74 / 3.26)$ & $2.34(0.30 / 4.37)$ & $3.34(1.34 / 5.34)$ \\
\hline $\mathrm{Q}_{4}[394]$ & $0.88(-1.13 / 2.88)$ & $3.97(1.97 / 5.97)$ & $1.15(-0.84 / 3.15)$ & $2.18(0.14 / 4.22)$ & $3.43(1.43 / 5.42)$ \\
\hline $\mathrm{p}^{2}$ & 0.120 & $<0.001$ & $<0.001$ & $<0.001$ & 0.314 \\
\hline \multicolumn{6}{|c|}{ Quartile of dietary fiber intake ${ }^{3}$} \\
\hline $\mathrm{Q}_{1}[36.4]$ & $0.87(-1.14 / 2.89)$ & $4.88(2.88 / 6.88)$ & $1.41(-0.59 / 3.40)$ & $2.85(0.82 / 4.89)$ & $3.47(1.47 / 5.47)$ \\
\hline $\mathrm{Q}_{2}[48.6]$ & $0.81(-1.21 / 2.83)$ & $4.57(2.57 / 6.57)$ & $1.38(-0.62 / 3.38)$ & $2.59(0.56 / 4.62)$ & $3.31(1.31 / 5.31)$ \\
\hline $\mathrm{Q}_{3}[61.7]$ & $0.82(-1.19 / 2.84)$ & $4.13(2.13 / 6.14)$ & $1.25(-0.74 / 3.25)$ & $2.27(0.24 / 4.29)$ & $3.29(1.30 / 5.29)$ \\
\hline $\mathrm{Q}_{4}[80.7]$ & $0.84(-1.17 / 2.86)$ & $3.99(1.99 / 5.99)$ & $1.17(-0.83 / 3.16)$ & $2.19(0.14 / 4.23)$ & $3.41(1.41 / 5.41)$ \\
\hline $\mathrm{p}^{2}$ & 0.235 & $<0.001$ & $<0.001$ & $<0.001$ & 0.154 \\
\hline
\end{tabular}

$195 \%$ CI in parentheses. All models were adjusted simultaneously for age (5-year categories), BMI (4 categories), cigarette smoking (yes/no), alcohol intake (3 categories), physical activity (3 categories), energy intake, saturated fat, monounsaturated and polyunsaturated fatty acid, protein, energy, and dietary fiber intake (each in quartiles).

${ }^{2}$ Kruskal-Wallis H-test.

${ }^{3}$ Mean value for each quartile in brackets.

${ }^{4} \mathrm{GL}$ density was computed by dividing the dietary GL load by energy intake.

The calculated geometric mean concentrations of TG, total cholesterol, HDL, LDL cholesterol and the ratio of TC to HDL by quartiles of dietary GL, GL density, average dietary GI, carbohydrate and dietary fiber intake are shown in table 3.

The adjusted geometric mean plasma concentrations of total cholesterol, HDL, and LDL cholesterol decreased across the quartiles of dietary GL, carbohydrate and di- etary fiber intake. While the associations with GL density and average GI, respectively, were inconsistent. For the lowest and the highest quartiles of GL the multivariate-adjusted geometric mean total cholesterol concentrations were 4.92 and $3.97 \mathrm{mmol} / \mathrm{l}$, whereas the geometric mean HDL cholesterol concentrations were 1.44 and 1.15 $\mathrm{mmol} / \mathrm{l}$ and the geometric mean LDL cholesterol concentrations were 2.87 and $2.18 \mathrm{mmol} / \mathrm{l}$, respectively. For the 
lowest and the highest quartiles of carbohydrate intake the multivariate-adjusted geometric mean total cholesterol concentrations were 4.93 and $3.97 \mathrm{mmol} / \mathrm{l}$, whereas the geometric mean HDL cholesterol concentrations were 1.44 and $1.15 \mathrm{mmol} / \mathrm{l}$ and the geometric mean LDL cholesterol concentrations were 2.90 and $2.18 \mathrm{mmol} / \mathrm{l}$, respectively. For the lowest and the highest quartiles of dietary fiber intake the multivariate-adjusted geometric mean total cholesterol concentrations were 4.88 and 3.99 $\mathrm{mmol} / \mathrm{l}$, whereas the geometric mean HDL cholesterol concentrations were 1.41 and $1.17 \mathrm{mmol} / \mathrm{l}$ and the geometric mean LDL cholesterol concentrations were 2.85 and $2.19 \mathrm{mmol} / \mathrm{l}$, respectively.

However, statistically significant associations or trends were not observed for GI, GL, the intake of carbohydrates, and plasma TG concentrations.

\section{Discussion}

In the present study conducted with adult vegans from Germany it was assumed that a vegan diet is characterized by a low GI and GL. The average dietary GI of the GVS study population was 51. Compared to the results of several observational studies [10-18], the overall GI of the vegan diet seems to be low and, therefore, may be one factor to explain the lower risk for $\mathrm{CHD}$ and type 2 diabetes of vegan subjects in comparison to omnivores [25]. However, it is difficult to accurately compare the mean GIs in the different studies, because different GI values (glucose- or white bread-based) are used. While we have taken glucose-based values, eight of the observational studies cited above [10-18] either did not indicate which one they used or stated they used white bread-based values. Only the study of Amano et al. [15] used glucose-based values as we did in our study. When taking the conversion factor of approximately $\sim 0.7$ into account to convert white bread-into glucose-based GI values [37], the average GI of the GVS study falls within the lowest GI quintile of the most observational studies. For example, in the Nurses' Health Study (NHS) with 65,173 participants, the lowest GI quintile was 64 and this was associated with the lowest risk for diabetes mellitus type 2 [10]. Similar results were observed in a cohort study with 42,759 men, who were $40-75$ years old. In this study, the dietary GI of the lowest quintile was 65 [16]. After adjustment for age, BMI, smoking, physical activity, family history of diabetes, alcohol consumption, cereal fiber, and total energy intake, the relative risk for diabetes mellitus type 2 was $37 \%$ lower in the lowest GI quintile compared with the highest quintile of GI [16]. The cohort study of Schulze et al. [18] supports our assumption that the GI of a vegan diet is rather low. In this large study with 91,249 women the lowest GI quintile was 70 . This quintile was associated with a $60 \%$ lower multivariate relative risk for diabetes mellitus type 2 . In addition in the cohort study by Liu et al. [12], using data from 10 years of follow-up on 75,000 women, the GI of the lowest quintile was 72 .

The average dietary GL of the GVS cohort was 144. In comparison to the findings from observational studies with omnivores $[12,14,15,39]$ the reported GL with the vegan diet was low to moderate. For example, in the total cohort of the NHS the mean value for the lowest and highest quintile of GL was 117 and 206, respectively. In this study the GL and the risk of CHD were positively associated - even after multiple adjustments were made [12].

Since there are associations between higher dietary GI or GL and risk for CHD disease [11-15, 39, 40] the relations of dietary GI and GL to plasma concentrations of lipoproteins such as total cholesterol, HDL, LDL cholesterol, the ratio of TC:HDL, and TG were examined. Contrary to the results of several observational studies [11, 14, $15,40]$, there were no significant associations between TG, total cholesterol, HDL, LDL, TC:HDL, and the average GI in the GVS study population. This observation may be explained by the fact that there is only a small difference between the lowest (Q1: 46) and highest (Q4: 57) quartile of dietary GI in our vegan study population. Therefore, all quartiles are characterized by a low GI when compared to the studies of Frost et al. [11], Liu et al. [14], and Amano et al. [15]. For this reason, the GVS results are not surprising, since all vegan subjects consumed a low-GI diet. In this context a recent meta-analysis is of interest. In this analysis of 14 randomized controlled trials of low-GI versus high-GI diets, low-GI diets caused a statistically significant improvement in total cholesterol concentrations, while there were no significant effects on LDL, HDL cholesterol and TG [41]. This indicates that the influence of the overall dietary GI on markers of lipid metabolism still remains controversial.

In our study the adjusted geometric mean plasma concentrations of cholesterol, HDL and LDL cholesterol decreased across the quartiles of dietary GL while there was no significant correlation between GL and TG. Except for HDL cholesterol, this result is in contrast to the findings of other investigators [13-15, 40]. For example, in the NHS cohort of Liu et al. [14] a significant rise of TG was observed with increasing GL. Furthermore, GL remained a significant predictor of fasting TG concentrations. Be- 
cause GL is defined as the product of GI and carbohydrate content $[10,16]$, carbohydrate intake of the GVS cohort is of interest. With a mean intake of $274 \mathrm{~g} /$ day (57.1 energy $\%)$ the diet of the subjects in our study is comparatively high in carbohydrates. In observational studies like the postmenopausal female subcohort of the NHS, ascending quintiles of carbohydrate intake were associated with increasing TG concentrations [14]. In addition, total carbohydrate intake was inversely associated with HDL cholesterol concentrations [40].

Data from metabolic studies support the observation that high-carbohydrate diets increase TG or reduce HDL cholesterol and therefore could translate into a higher risk of CHD [42, 43]. However, our results and those of Goff et al. [35] show that vegan diets rich in carbohydrates are not or only partially associated with such negative effects on the lipid profile. Other studies have shown that the HDL cholesterol reduction and rise of TG seen with some high-carbohydrate diets may be short-term effects $[44,45]$ and depends mainly on the carbohydrate quality of such diets. For example, Harbis et al. [46] studied two mixed meals that were reasonably matched for macronutrient composition but differed in their content of slowly available glucose (flake-based versus biscuitbased meal). The plasma TG and the apolipoprotein B100 and B-48 concentration increased significantly after the flakes meal (high GI) but not after the biscuit meal (low GI) in obese, insulin-resistant subjects. Similar results were observed in healthy individuals with different GI meals [47]. A recently published randomized trial of overweight or obese adults with dyslipidemia or fasting hyperglycemia shows no significant undesirable effects of a high-carbohydrate, low-GI diet (Ornish) on TG and HDL cholesterol when compared with a low-carbohydrate diet (Atkins) [48]. Furthermore, a reduction in the overall dietary GI by at least 12 units reduces the TG concentration by approximately $9 \%$ in 10 of 11 long-term studies lasting from 1 week to 3 months [49]. Other investigators have shown that a high-carbohydrate, but low-GI diet significantly increased HDL cholesterol concentrations compared to an isocaloric high-carbohydrate diet with a high GI [50].

The exact mechanisms related to lipid modulation by low-GI diets still remain poorly understood. It is known that the glycemic and insulinemic response after consumption of a low-GI meal is relatively slow compared to a high-GI meal [51-53]. The resulting comparatively low insulin concentration after a low-GI meal may reduce the insulin-stimulated HMG-CoA reductase activity and thus may reduce cholesterol synthesis [24]. Another pos- sible mechanism is that the low insulin response could modulate VLDL synthesis in a favorable way [46].

Because the low-GI vegan diet of our subjects was based on minimally processed plant foods like fresh fruits, vegetables, whole grain products, legumes, and nuts [30], the low GI observed in this study is only one aspect of such a carbohydrate-rich diet. Concerning the risk factors of CHD such as plasma lipids (LDL, HDL cholesterol), another important aspect is the high fiber intake (56.7 g/day) observed in our study. In the GVS study population the adjusted geometric mean plasma concentrations of total cholesterol, HDL and LDL cholesterol decreased across the quartiles of dietary fiber intake. Except for HDL cholesterol, these findings are consistent with the results of several observational as well as clinical studies which have shown favorable effects of fiber-rich diets on the lipid profile. Especially soluble fiber abundant in fruits, legumes, and oat cereals exhibit LDL cholesterol-lowering properties and reduce TG levels [54]. A meta-analysis from 10 prospective cohort studies supported the $\mathrm{CHD}$ protective effect of a fiber-rich vegan diet. In this analysis dietary fiber from cereals and fruits was inversely associated with the risk of CHD [55]. Of course, there are a lot of other bioactive components in a vegan diet that alter plasma lipoproteins and TG. For example, phytosterols, monounsaturated fatty acids and vegetable protein in nuts have LDL cholesterol-lowering effects $[56,57]$.

Furthermore, the vegan diet in our study collective was characterized by a low intake of saturated fatty acids $(6.0 \pm 1.7$ energy \%) and dietary cholesterol (21.5 \pm 27.0 $\mathrm{mg} /$ day), which may have a favorable impact on lipid profile. The multivariate analysis of the data allowed for considering some of these confounders by including them in the analysis.

Taking our data together with a series of clinical studies conducted from the Jenkins group [58-60] and the Ornish group [61-64] with high-fiber, carbohydrate-rich and low-GI diets, our results support the assumption that carbohydrate quality, not quantity is primarily important for lipid markers and CHD risk reduction. From the background of the current low-carbohydrate debate, our results, therefore, may be of interest for public health.

The most important limitation that should be mentioned when examining the results of this study is the use of a FFQ, which was not specifically designed to assess GI and GL. But this limitation occurs in some other studies as well [18]. Furthermore, the overall accuracy of the measurement of food intake via FFQ in general [65] and particularly the validity in view of measures the GI and 
GL of the diet [66] have been questioned. Because FFQs have substantial limitations [67], the above-mentioned questions arise also when interpreting the results of this study. However, up to now, the FFQ is the standard tool for dietary assessment in all large epidemiological studies and the results of those studies are still relevant $[68,69]$. Another limitation is the measurement of surrogate markers (i.e. lipid parameters) instead of CHD endpoints such as CHD-related mortality or cardiac events. Also the relatively small number of vegan persons in this study might weaken the power of our results. To our knowledge, publications from the British EPIC cohort (e.g. Davey et al. [70]) are the first data source with a vegan sample size of more than 250 persons, while other studies on vegetarian and vegan cohorts have smaller sample sizes too - not at least due to the small number of vegans found in a population.

\section{Conclusion}

A vegan diet including large amounts of fruit, vegetables, whole grains, legumes, and nuts is characterized by a low GI and GL. Especially the latter is associated with decreased total and LDL cholesterol plasma concentrations which are expected to be cardioprotective in the long run. Overall, these data do not support the hypothesis that a carbohydrate-rich diet per se is associated with unfavorable effects on TG that would be predicted to increase the risk of CHD.

\section{Acknowledgments}

Eden Foundation, Bad Soden, Germany and Stoll VITA Foundation, Waldshut-Tiengen, Germany.

\section{References}

1 Sans S, Kesteloot H, Kromhout D: The burden of cardiovascular diseases mortality in Europe. Task Force of the European Society of Cardiology on Cardiovascular Mortality and Morbidity Statistics in Europe. Eur Heart J 1997;18:1231-1248.

2 Klein S, Sheard NF, Pi-Sunyer X, Daly A, Wylie-Rosett J, Kulkarni K, Clark NG; American Diabetes Association; North American Association for the Study of Obesity; American Society for Clinical Nutrition: Weight management through lifestyle modification for the prevention and management of type 2 diabetes: rationale and strategies. A statement of the American Diabetes Association, the North American Association for the Study of Obesity, and the American Society for Clinical Nutrition. Am J Clin Nutr 2004;80:257-263.

-3 Mokdad AH, Bowman BA, Ford ES, Vinicor F, Marks JS, Koplan JP: The continuing epidemics of obesity and diabetes in the United States. JAMA 2001;286:1195-1200.

$4 \mathrm{Hu}$ FB, Willett WC: Optimal diets for prevention of coronary heart disease. JAMA 2002;288:2569-2578.

5 Key TJ, Schatzkin A, Willett WC, Allen NE, Spencer EA, Travis RC: Diet, nutrition and the prevention of cancer. Public Health Nutr 2004;7:187-200.

6 FAO/WHO Report: Carbohydrate in human nutrition. Report of a Joint FAO/WHO Expert Consultation. FAO Food Nutr Pap 1989; $66: 1-140$
7 Jenkins DJ, Wolever TM, Taylor RH, Barker $\mathrm{H}$, Fielden $\mathrm{H}$, Baldwin JM, Bowling AC, Newman HC, Jenkins AL, Goff DV: Glycemic index of foods: a physiological basis for carbohydrate exchange. Am J Clin Nutr 1981;34:362-366.

-8 Wolever TM, Jenkins DJ, Jenkins AL, Josse RG: The glycemic index: methodology and clinical implications. Am J Clin Nutr 1991; 54:846-854.

9 Ludwig DS: The glycemic index: physiological mechanisms relating to obesity, diabetes, and cardiovascular disease. JAMA 2002;287: 2414-2423.

10 Salmeron J, Manson JE, Stampfer MJ, Colditz GA, Wing AL, Willett WC: Dietary fibre, glycemic load, and risk of non-insulin-dependent diabetes mellitus in women. JAMA 1997;277:472-477.

11 Frost G, Leeds AA, Dore CJ, Madeiros S, Brading S, Dornhorst A: Glycaemic index as a determinant of serum HDL-cholesterol concentration. Lancet 1999;353:1045-1048.

$\checkmark 12$ Liu S, Willett WC, Stampfer MJ, Hu FB, Franz M, Sampson L, Hennekens CH, Manson JE: A prospective study of dietary glycemic load, carbohydrate intake, and risk of coronary heart disease in US women. Am Clin Nutr 2000;71:1455-1461.

13 Ford ES, Liu S: Glycemic index and serum high-density lipoprotein cholesterol concentration among US adults. Arch Intern Med 2001;161:572-576.
4 Liu S, Manson JE, Stampfer MJ, Holmes MD, Hu FB, Hankinson SE, Willett WC: Dietary glycemic load assessed by food-frequency questionnaire in relation to plasma highdensity lipoprotein cholesterol and fasting plasma triacylglycerols in postmenopausal women. Am J Clin Nutr 2001;73:560-566.

15 Amano Y, Kawakubo K, Lee JS, Tang AC, Sugiyama M, Mori K: Correlation between dietary glycemic index and cardiovascular disease risk factors among Japanese women. Eur J Clin Nutr 2004;58:1472-1478.

16 Salmeron J, Ascherio A, Rimm EB, Colditz GA, Spiegelman D, Jenkins DJ, Stampfer MJ, Wing AL, Willett WC: Dietary fibre, glycemic load, and risk of NIDDM in men. Diabetes Care 1997;20:545-550.

$17 \mathrm{Hu}$ FB, Manson JE, Stampfer MJ, Colditz G, Liu S, Solomon CG, Willett WC: Diet, lifestyle, and the risk of type 2 diabetes mellitus in women. N Engl J Med 2001;345:790-797.

$\checkmark 18$ Schulze MB, Liu S, Rimm EB, Manson JE, Willett WC, Hu FB: Glycemic index, glycemic load, and dietary fibre intake and incidence of type 2 diabetes in younger and middle-aged women. Am J Clin Nutr 2004;80: 348-356.

19 Jenkins DJ, Wolever TM, Collier GR, Ocana A, Rao AV, Buckley G, Lam Y, Mayer A, Thompson LU: Metabolic effects of a lowglycemic-index diet. Am J Clin Nutr 1987;46: 968-975. 
20 Jenkins DJ, Wolever TM, Kalmusky J, Guidici S, Giordano C, Patten R, Wong GS, Bird JN, Hall M, Buckley G, et al.: Low-glycemic index diet in hyperlipidemia: use of traditional starchy foods. Am J Clin Nutr 1987;46: 66-71.

-21 Wolever TM, Jenkins DJ, Vuksan V, Jenkins AL, Buckley GC, Wong GS, Josse RG: Beneficial effect of a low glycaemic index diet in type 2 diabetes. Diabet Med 1992;9:451458.

-22 Wolever TM, Jenkins DJ, Vuksan V, Jenkins AL, Wong GS, Josse RG: Beneficial effect of low-glycemic index diet in overweight NIDDM subjects. Diabetes Care 1992;15:562564.

-23 Sloth B, Krog-Mikkelsen I, Flint A, Tetens I, Bjorck I, Vinoy S, Elmstahl H, Astrup A, Lang V, Raben A: No difference in body weight decrease between a low-glycemic-index and a high-glycemic-index diet but reduced LDL cholesterol after 10-weeks ad libitum intake of the low-glycemic-index diet. Am J Clin Nutr 2004;80:337-347.

24 Augustin LS, Franceschi S, Jenkins DJ, Kendall CW, La Vecchia C: Glycemic index in chronic disease: a review. Eur J Clin Nutr 2002;56:1049-1071.

25 Key TJ, Fraser GE, Thorogood M, Appleby PN, Beral V, Reeves G, Burr ML, ChangClaude J, Frentzel-Beyme R, Kuzma JW, Mann J, McPherson K: Mortality in vegetarians and nonvegetarians: detailed findings from a collaborative analysis of 5 prospective studies. Am J Clin Nutr 1999;70(suppl 3): 516S-524S.

26 Segasothy M, Phillips PA: Vegetarian diet: panacea for modern lifestyle diseases? QJM 1999;92:531-544.

27 Jenkins DJ, Kendall CW, Marchie A, Jenkins AL, Augustin LS, Ludwig DS, Barnard ND, Anderson JW: Type 2 diabetes and the vegetarian diet. Am J Clin Nutr 2003;78(suppl 3):610S-616S.

28 Leitzmann C: Vegetarian diets: what are the advantages? Forum Nutr 2005;57:147-156.

29 Haddad EH, Tanzman JS: What do vegetarians in the United States eat? Am J Clin Nutr 2003;78(suppl 3):626S-632S.

-30 Waldmann A, Koschizke JW, Leitzmann C, Hahn A: Dietary intakes and lifestyle factors of a vegan population in Germany: results from the German Vegan Study. Eur J Clin Nutr 2003;57:947-955.

31 Sabaté J: The contribution of vegetarian diets to health and disease: a paradigm shift? Am J Clin Nutr 2003;78(suppl 3):502S-507S.

32 Singh PN, Sabaté J, Fraser GE: Does low meat consumption increase life expectancy in humans? Am J Clin Nutr 2003;78(suppl 3): 526S-532S.

- 33 Waldmann A, Koschizke JW, Leitzmann C, Hahn A: Homocysteine and cobalamin status in German vegans. Public Health Nutr 2004;7:467-472.
34 Waldmann A, Koschizke JW, Leitzmann C, Hahn A: Dietary iron intake and iron status of German female vegans: results of the German Vegan Study. Ann Nutr Metab 2004;48: 103-108.

35 Goff LM, Bell JD, So PW, Dornhorst A, Frost GS: Veganism and its relationship with insulin resistance and intramyocellular lipid. Eur J Clin Nutr 2004;9:291-298.

-36 Koebnick C, Strassner C, Hoffmann I, Leitzmann C: Consequences of a long-term raw food diet on body weight and menstruation: results of a questionnaire survey. Ann Nutr Metab 1999;43:69-79.

-37 Foster-Powell K, Holt SH, Brand-Miller JC: International table of glycemic index and glycemic load values: 2002. Am J Clin Nutr 2002;76:5-56.

38 Buyken AE, Toeller M, Heitkamp G, Karamanos B, Rottiers R, Muggeo M, Fuller JH; EURODIAB IDDM Complications Study Group: Glycemic index in the diet of European outpatients with type 1 diabetes: relations to glycated hemoglobin and serum lipids. Am J Clin Nutr 2001;73:574-581.

39 Liu S, Manson JE, Buring JE, Stampfer MJ, Willett WC, Ridker PM: Relation between a diet with a high glycemic load and plasma concentrations of high-sensitivity C-reactive protein in middle-aged women. Am J Clin Nutr 2002;75:492-498.

40 Slyper A, Jurva J, Pleuss J, Hoffmann R, Gutterman D: Influence of glycemic load on HDL cholesterol in youth. Am J Clin Nutr 2005;81:376-379.

41 Opperman AM, Venter CS, Oosthuizen W, Thompson RL, Vorster HH: Meta-analysis of the health effects of using the glycaemic index in meal-planning. Br J Nutr 2004;92: 367-381.

42 Austin MA, Hokanson JE, Edwards KL: Hypertriglyceridemia as a cardiovascular risk factor. Am J Cardiol 1998;81:7B-12B.

43 Mensink RP, Zock PL, Kester AD, Katan MB Effects of dietary fatty acids and carbohydrates on the ratio of serum total to HDL cholesterol and on serum lipids and apolipoproteins: a meta-analysis of 60 controlled trials. Am J Clin Nutr 2003;77:1146-1155.

44 Lees RS, Fredrickson DS: Carbohydrate induction of hyperlipemia in normal men. Clin Res 1965;13:327.

45 Heilbronn LK, Noakes M, Clifton PM: Effect of energy restriction, weight loss, and diet composition on plasma lipids and glucose in patients with type 2 diabetes. Diabetes Care 1999;22:889-895.

46 Harbis A, Perdreau S, Vincent-Baudry S, Charbonnier M, Bernard MC, Raccah D, Senft M, Lorec AM, Defoort C, Portugal H, Vinoy S, Lang V, Lairon D: Glycemic and insulinemic meal responses modulate postprandial hepatic and intestinal lipoprotein accumulation in obese, insulin-resistant subjects. Am J Clin Nutr 2004;80:896-902.
47 Harbis A, Defoort C, Narbonne H, Juhel C, Senft M, Latge C, Delenne B, Portugal H, Atlan-Gepner C, Vialettes B, Lairon D: Acute hyperinsulinism modulates plasma apolipoprotein B-48 triglyceride-rich lipoproteins in healthy subjects during the postprandial period. Diabetes 2001;50:462-469.

48 Dansinger ML, Gleason JA, Griffith JL, Selker HP, Schaefer EJ: Comparison of the Atkins, Ornish, Weight Watchers, and Zone diets for weight loss and heart disease risk reduction: a randomized trial. JAMA 2005; 293:43-53.

49 Brand Miller JC: Importance of glycemic index in diabetes. Am J Clin Nutr 1994;59(suppl 3):747S-752S.

50 Luscombe ND, Noakes M, Clifton PM: Diets high and low in glycemic index versus high monounsaturated fat diets: effects on glucose and lipid metabolism in NIDDM. Eur J Clin Nutr 1999;53:473-478.

51 Wolever TM, Bolognesi C: Prediction of glucose and insulin responses of normal subjects after consuming mixed meals varying in energy, protein, fat, carbohydrate and glycemic index. J Nutr 1996;126:2807-2812.

52 Bjorck I, Liljeberg H, Ostman E: Low glycaemic-index foods. Br J Nutr 2000;83(suppl 1):149S-155S

53 Englyst KN, Vinoy S, Englyst HN, Lang V: Glycaemic index of cereal products explained by their content of rapidly and slowly available glucose. Br J Nutr 2003;89:329340.

54 Lupton JR, Turner ND: Dietary fibre and coronary disease: does the evidence support an association? Curr Atheroscler Rep 2003; 5:500-505

-55 Pereira MA, O’Reilly E, Augustsson K, Fraser GE, Goldbourt U, Heitmann BL, Hallmans G, Knekt P, Liu S, Pietinen P, Spiegelman D, Stevens J, Virtamo J, Willett WC, Ascherio A: Dietary fibre and risk of coronary heart disease: a pooled analysis of cohort studies. Arch Intern Med 2004; 164 : 370-376.

56 Morgan WA, Clayshulte BJ: Pecans lower low-density lipoprotein cholesterol in people with normal lipid levels. J Am Diet Assoc 2000;100:312-318

57 Sabaté J, Haddad E, Tanzman JS, Jambazian P, Rajaram S: Serum lipid response to the graduated enrichment of a step I diet with almonds: a randomized feeding trial. Am J Clin Nutr 2003;77:1379-1384.

-58 Kendall CW, Jenkins DJ: A dietary portfolio: maximal reduction of low-density lipoprotein cholesterol with diet. Curr Atheroscler Rep 2004;6:492-498.

59 Lamarche B, Desroches S, Jenkins DJ, Kendall CW, Marchie A, Faulkner D, Vidgen E, Lapsley KG, Trautwein EA, Parker TL, Josse RG, Leiter LA, Connelly PW: Combined effects of a dietary portfolio of plant sterols, vegetable protein, viscous fibre and almonds on LDL particle size. Br J Nutr 2004;92:657663. 
-60 Jenkins DJ, Kendall CW, Marchie A, Faulkner DA, Wong JM, de Souza R, Emam A, Parker TL, Vidgen E, Trautwein EA, Lapsley KG, Josse RG, Leiter LA, Singer W, Connelly PW: Direct comparison of a dietary portfolio of cholesterol-lowering foods with a statin in hypercholesterolemic participants. Am J Clin Nutr 2005;81:380-387.

-61 Ornish D, Brown SE, Scherwitz LW, Billings JH, Armstrong WT, Ports TA, McLanahan SM, Kirkeeide RL, Brand RJ, Gould KL: Can lifestyle changes reverse coronary heart disease? The Lifestyle Heart Trial. Lancet 1990; 336:129-133.

-62 Ornish D, Scherwitz LW, Billings JH, Brown SE, Gould KL, Merritt TA, Sparler S, Armstrong WT, Ports TA, Kirkeeide RL, Hogeboom C, Brand RJ: Intensive lifestyle changes for reversal of coronary heart disease. JAMA 1998;280:2001-2007.
63 Gould KL, Ornish D, Scherwitz L, Brown S, Edens RP, Hess MJ, Mullani N, Bolomey L, Dobbs F, Armstrong WT, et al: Changes in myocardial perfusion abnormalities by positron emission tomography after long-term, intense risk factor modification. JAMA 1995;274:894-901.

64 Koertge J, Weidner G, Elliott-Eller M, Scherwitz L, Merritt-Worden TA, Marlin R, Lipsenthal L, Guarneri M, Finkel R, Saunders DE Jr, McCormac P, Scheer JM, Collins RE, Ornish D: Improvement in medical risk factors and quality of life in women and men with coronary artery disease in the Multicenter Lifestyle Demonstration Project. Am J Cardiol 2003;91:1316-1322.
65 Kristal AR, Peters U, Potter JD: Is it time to abandon the Food Frequency Questionnaire? Cancer Epidemiol Biomarkers Prev 2005; 14:2826-2829.

66 Pi-Sunyer FX: Glycemic index and disease. Am J Clin Nutr 2002;76:290S-298S

-67 Byers T: Food frequency dietary assessment: how bad is good enough? Am J Epidemiol 2001;154:1087-1088.

68 Kelemen LE: Food frequency questionnaires: not irrelevant yet. Cancer Epidemiol Biomarkers Prev 200615:1054.

69 Willett WC, Hu FB: Not the time to abandon the food frequency questionnaire: point. Cancer Epidemiol Biomarkers Prev 2006;15: 1757-1758

70 Davey GK, Spencer EA, Appleby PN, Allen NE, Knox KH, Key TJ: EPIC-Oxford: lifestyle characteristics and nutrient intakes in a cohort of 33,883 meat-eaters and 31,546 non meat-eaters in the UK. Public Health Nutr 2003;6:259-269. 